\title{
Clinical, Immunological, and Molecular Variability of RAG Deficiency: A Retrospective Analysis of 22 RAG Patients
}

\author{
Cristina Cifaldi ${ }^{1}$ (D) B Beatrice Rivalta ${ }^{1,2} \cdot$ Donato Amodio $^{3} \cdot$ Algeri Mattia $^{4} \cdot$ Lucia Pacillo $^{1,2} \cdot$ Silvia Di Cesare $^{1,2}$. \\ Maria Chiriaco $^{2}$ - Giorgiana Madalina Ursu ${ }^{2}$ - Nicola Cotugno ${ }^{2,3}$. Carmela Giancotta ${ }^{3}$ Emma C. Manno ${ }^{3}$. \\ Veronica Santilli ${ }^{3}$. Paola Zangari ${ }^{3}$. Galaverna Federica ${ }^{4}$. Giuseppe Palumbo $o^{2,4}$. Pietro Merli ${ }^{4}$ Paolo Palma ${ }^{2,3}$. \\ Paolo Rossi ${ }^{1,2,3}$. Gigliola Di Matteo ${ }^{1,2}$. Franco Locatelli ${ }^{4,5}$. Andrea Finocchi ${ }^{1,2}$. Caterina Cancrini ${ }^{1,2}$
}

Received: 1 June 2021 / Accepted: 29 August 2021 / Published online: 18 October 2021

(c) The Author(s) 2021

\begin{abstract}
Purpose We described clinical, immunological, and molecular characterization within a cohort of 22 RAG patients focused on the possible correlation between clinical and genetic data.

Methods Immunological and genetic features were investigated by multiparametric flow cytometry and by Sanger or next generation sequencing (NGS) as appropriate.

Results Patients represented a broad spectrum of RAG deficiencies: SCID, OS, LS/AS, and CID. Three novel mutations in $R A G 1$ gene and one in $R A G 2$ were reported. The primary symptom at presentation was infections $(81.8 \%)$. Infections and autoimmunity occurred together in the majority of cases $(63.6 \%)$. Fifteen out of $22(68.2 \%)$ patients presented autoimmune or inflammatory manifestations. Five patients experienced severe autoimmune cytopenia refractory to different lines of therapy. Total lymphocytes count was reduced or almost lacking in SCID group and higher in OS patients. B lymphocytes were variably detected in LS/AS and CID groups. Eighteen patients underwent HSCT permitting definitive control of autoimmune/ hyperinflammatory manifestations in twelve of them $(80 \%)$.

Conclusion We reinforce the notion that different clinical phenotype can be found in patients with identical mutations even within the same family. Infections may influence genotype-phenotype correlation and function as trigger for immune dysregulation or autoimmune manifestations. Severe and early autoimmune refractory cytopenia is frequent and could be the first symptom of onset. Prompt recognition of RAG deficiency in patients with early onset of autoimmune/hyperinflammatory manifestations could contribute to the choice of a timely and specific treatment preventing the onset of other complications.
\end{abstract}

Keywords RAG deficiency · RAG1/RAG2 $\cdot$ Hypomorphic mutation · CID phenotypes · Cytopenia

\begin{tabular}{l} 
Cristina Cifaldi and Beatrice Rivalta shared co-first authorship. \\
\hline Donato Amodio and Algeri Mattia shared co-second authorship. \\
\hline Cristina Cifaldi \\
cristina.cifaldi@gmail.com; cristina.cifaldi@opgb.net \\
Caterina Cancrini \\
cancrini@med.uniroma2.it; caterina.cancrini@opbg.net \\
Academic Department of Pediatrics (DPUO), Immune \\
and Infectious Diseases Division, Research Unit of Primary \\
Immunodeficiencies, Bambino Gesù Children's Hospital, \\
IRCCS, 00165 Rome, Italy \\
Chair of Pediatrics, Department of Systems Medicine, \\
University of Rome “Tor Vergata”, via Montpellier, 1, \\
00133 Rome, Italy
\end{tabular}

\begin{tabular}{|c|c|}
\hline \multicolumn{2}{|c|}{ Abbreviations } \\
\hline TCR & T-cell receptor \\
\hline SCID & Severe combined immunodeficiency \\
\hline $\mathrm{OS}$ & Omenn syndrome \\
\hline
\end{tabular}

3 Academic Department of Pediatrics (DPUO), Research Unit of Clinical Immunology and Vaccinology, Bambino Gesù Children's Hospital, IRCCS, 00165 Rome, Italy

4 Department of Pediatric Hemato-Oncology and Cell and Gene Therapy, Scientific Institute for Research and Healthcare, Bambino Gesù Children's Hospital, IRCCS, 00165 Rome, Italy

5 Department of Pediatrics, Sapienza, University of Rome, Rome, Italy 


$\begin{array}{ll}\text { AS } & \text { Atypical SCID } \\ \text { LS } & \text { Leaky/SCID } \\ \text { CID/G/A } & \begin{array}{l}\text { Combined immunodeficiency with diffuse } \\ \text { granulomatous disease and/or autoimmunity }\end{array} \\ \text { EBV } & \begin{array}{l}\text { Epstein-Barr virus } \\ \text { CVID }\end{array} \\ \text { Common variable immunodeficiency } \\ \text { ICL } & \text { Idiopathic CD4 + T cell lymphopenia } \\ \text { NGS } & \text { Next generation sequencing } \\ \text { RTE } & \text { Recent thymic emigrants } \\ \text { IUIS } & \text { Union of immunological societies } \\ \text { PIDTC } & \text { Primary immune deficiency treatment } \\ & \text { consortium } \\ \text { CMV } & \text { Cytomegalovirus } \\ \text { IVIG } & \text { Intravenous immunoglobulin } \\ \text { ITP } & \text { Immune thrombocytopenia } \\ \text { AIHA } & \text { Autoimmune hemolytic anemia } \\ \text { HSCT } & \text { Hematopoietic stem cell transplantation } \\ \text { MAV } & \text { Myeloablative conditioning } \\ \text { MMF } & \text { Mycophenolate mofetil } \\ \text { aGvHD } & \text { Acute graft-versus-host disease }\end{array}$

\section{Introduction}

Systematic rearrangement of antigen receptor genes via $\mathrm{V}(\mathrm{D}) \mathrm{J}$ recombination is essential for maturation of progenitor lymphocytes, the genesis of immunoglobulin and $\mathrm{T}$ cell receptor (TCR), and production of a broad repertoire of antigen-specific T and B cells [1-6]. Complete RAGs deficiency has been known to cause severe combined immunodeficiency (SCID) phenotype with lack of $\mathrm{T}$ and $\mathrm{B}$ cells (T-B-NK+ SCID) [7], life-threatening infections, and failure to thrive in early infancy. Today, RAGs diseases are associated to an expanding broad spectrum of phenotypes ranging from SCID, Omenn syndrome (OS) [8-13], "leaky" or "atypical" SCID, (LS/AS) whose peculiarities reside in varying numbers of oligoclonal $\mathrm{T}$ and $\mathrm{B}$ cells, and in some cases a predominance of $\gamma \delta+$ T cells ( $\gamma \delta$ AS) and autoimmune cytopenias [14]. Hypomorphic mutations allowing a residual RAG protein function may lead to a later onset of different diseases and a risk of delayed diagnosis. These forms can be characterized by diffuse granulomatous disease and/or autoimmunity (CID-G/AI) and an altered response to severe Herpesviridae infections (in particular EBV) [15-17]. Otherwise, common variable immunodeficiency (CVID), idiopathic CD4+ T cell lymphopenia (ICL) [18], IgA deficiency, and hyper-IgM syndrome have been also reported [19-21].

Although infections are the predominant presenting features in RAG deficiency patients, autoimmune manifestations including cytopenia, autoimmune hepatitis, myopathy, and nephrotic syndrome [17, 22, 23] should be considered associated manifestations. In addition, patients may develop inflammation and immune dysregulation symptoms as dermatitis or lymphoproliferation due to hyperinflammation and altered lymphocyte homeostasis [30].

This autoimmunity has been linked not only to checkpoint breaks in both $\mathrm{T}$ and $\mathrm{B}$ cell tolerance but also to other mechanisms which may play an additional role in sustaining autoimmune pathology [24].

Herein, we report the clinical and immunological phenotype together with molecular characterization of 22 RAG patients referred to our center presenting with a broad spectrum of symptoms including autoimmune and/or hyperinflammatory manifestations.

\section{Methods}

\section{Patients}

A total of 22 patients from 18 different families were assessed between 2009 and 2020 at the Bambino Gesù Children's Hospital. Patients were classified into four groups (SCID, OS, LS/AS, CID) based on clinical presentation, immunological data, on the criteria published by the Primary Immune Deficiency Treatment Consortium (PIDTC) [25], ESID 2019 [26], and other groups [24, 27, 28].

- SCID: at least one of: invasive bacterial, viral, or fungal/ opportunistic infection; persistent diarrhoea and failure to thrive; affected family member AND manifestation in the first year of life AND two of $4 \mathrm{~T}$ cell criteria fulfilled: absence or very low number of T cells (CD3 T cells < 300/microliter), reduced naive CD4 and/or CD8 T cells; elevated $\gamma / \delta \mathrm{T}$ cells; no or very low T cell function by response to mitogen or TCR stimulation; AND T cells maternal engraftment excluded AND HIV excluded.

- OS: Desquamating erythroderma in the first year of life AND one of the following: lymphoproliferation, hepatomegaly splenomegaly; failure to thrive; chronic diarrhea; recurrent pneumonia AND eosinophilia or elevated $\mathrm{IgE}$ AND T-cell deficiency (detectable CD3 T cells, $\geq 300 /$ microliter, low naïve cells, reduced proliferation, oligoclonality) AND maternal engraftment excluded AND HIV excluded.

- LS/AS: Mutation in a SCID-causing gene AND Absence of characteristic SCID-associated infections (PCP, symptomatic CMV, persistent respiratory or gastrointestinal virus infection) in the first year of life AND does not fulfill criteria for Omenn syndrome. Reduced number of CD3 T cells (for age up to 2 years $<1000 /$ microliter; for $>2$ years up to 4 years $<800 /$ microliter, for $>4$ years $<$ $600 /$ microliter) AND Absence of maternal engraftment AND $<30 \%$ of lower limit of normal T cell function (as measured by response to PHA) AND Presence of 
activated, oligoclonal, and autologous T cells not associated with typical features of OS. Expansion of $\gamma \delta \mathrm{T}$ cells upon cytomegalovirus (CMV) infection or EpsteinBarr virus (EBV)-driven lymphoproliferative disease and autoimmune cytopenia could be associated.

- CID: at least one of: severe infection (especially VZV, CMV, EBV, HPV, and molluscum); one manifestation of immune dysregulation (autoimmunity, IBD, severe eczema, lymphoproliferation, granuloma); malignancy AND age $\geq 2$ years AND affected family member AND 2 of 4 T cell criteria fulfilled: reduced CD3 or CD4 or CD8 T cells (using age-related reference values); reduced naïve CD4 and/or CD8 T cells; elevated g/d T cells; reduced proliferation to mitogen or TCR stimulation.

The clinical and immunological characterization is summarized in Tables 1 and 2.

Two patients (PID-17 and PID-21) have been enrolled in the Profound CID study (pCID) (DRKS00000497), fulfilling the study inclusion criteria.

\section{Multiparametric Flow Cytometric Analysis}

All flow cytometric analyses were performed on ethylenediamine tetraacetic acid (EDTA) blood samples within $24 \mathrm{~h}$ of venipuncture. After red blood cell lysis with ammonium chloride, the lymphocytes were incubated with the appropriate antibody cocktail for $30 \mathrm{~min}$ at $4{ }^{\circ} \mathrm{C}$, washed with PBS, and suspended in PBS. At least 50,000 events in the lymphocyte live gate were acquired for each sample. Samples were acquired on FACSCANTO II (BD Biosciences, San Diego, CA, USA) and analyzed with FlowJo software (Tree Star Inc, version 8.8.6, Ashland, Ore).

\section{Genetic Analysis}

Ion Torrent Gene Target Library Preparation and NGS Sequencing were performed according to manufacturer's instructions (Thermo Fisher Scientific).

Next generation sequencing (Ion Torrent) and sequencing: genomic DNA is isolated from peripheral blood of patients using standard protocols (QIAamp DNA Blood kit by QIAGEN GmbH, Hilden, Germany). PCR reactions were carried out using GoTaq DNA polymerase by standard methods (Promega, Madison, WI). Direct sequencing was performed using the BigDye Terminator v3.1 Cycle Sequencing Kit (Applied Biosystems, Foster City, CA) and analyzed on an ABI PRISM 3130 and 310 automated sequencers (Applied Biosystems).

Sanger sequencing for all mutations and parents' carrier status was performed.

\section{Ion Torrent Bioinformatics Analysis}

Mapping and variant calling were performed using the Ion Torrent suite software v3.6. Sequencing reads were aligned against the USC hg19 reference genome using the program distributed within the Torrent mapping Alignment Program (TMAP) map4 algorithm (Thermo Fisher; https://github. com/iontorrent/TS). The aligned reads were processed for variant calling by using the Torrent Suite Variant Caller TVC program; variants found in Variant Calling Format (VCF) file were annotated using ANNOVAR. The called variants with minimum coverage of $\times 20$, standard Mapping Quality, and Base Phred Quality were examined on Integrative Genome Viewer (IGV) and BIOMART. After applying filtering criteria, all nonsense, frameshift, and canonical splice site variants were evaluated to determine their potential pathogenicity.

\section{Statistical Analysis}

Data were analyzed with Graph Pad Prism, version 6.2 (Graph Pad Software, La Jolla, CA). $p<0.05$ and $* * p<0.005$ were considered significant.

\section{Results}

\section{Clinical Phenotype and Genetic Characterization of RAG Cohort}

We report clinical, immunological, and molecular characterization within a cohort of 22 RAG patients diagnosed between 2009 and 2020.

The cohort characteristics are described in Table 1. The majority of patients ( 8 cases, $36.4 \%$ ) were affected by SCID presenting with T-B-NK+ phenotype except for two patients with $\mathrm{T}+\mathrm{B}-\mathrm{NK}+$ phenotype in which maternal $\mathrm{T}$ engraftment was observed (PID-5 and PID-8), followed by OS (6 cases, 27.2\%), LS/AS (4 cases, 18.2\%), and CID (4 cases, $18.2 \%$ ) (Fig. 1A, Tables 1 and 2). The age at presentation ranged from birth to 72 months, with a median of 5 months (range birth to 6 years), whereas the median age of genetic diagnosis was 6 months (range birth to 11 years).

In particular, the mean age of first symptom was 3.4 months $( \pm 0.25 \mathrm{sd})$ and confirming genetic diagnosis 4.6 months $( \pm 0.29 \mathrm{sd})$ for SCID, 2 months $( \pm 0.19 \mathrm{sd})$ and 3 months $( \pm 0.21 \mathrm{sd})$ for OS, 1 year $( \pm 0.55 \mathrm{sd})$ and 1.2 years $( \pm 0.53 \mathrm{sd})$ for LS/AS, and 3.2 years $( \pm 2.06 \mathrm{sd})$ and 6.7 years ( $\pm 4.7 \mathrm{sd}$ ) for CID (Fig. 1B). The number of $R A G$ diagnoses following NGS application changed from a median of 1.5 up to 2.6 per year (Fig. 1C). Noteworthy, there was no significant difference between patients with SCID and OS when comparing age at first clinical symptoms and at diagnosis 


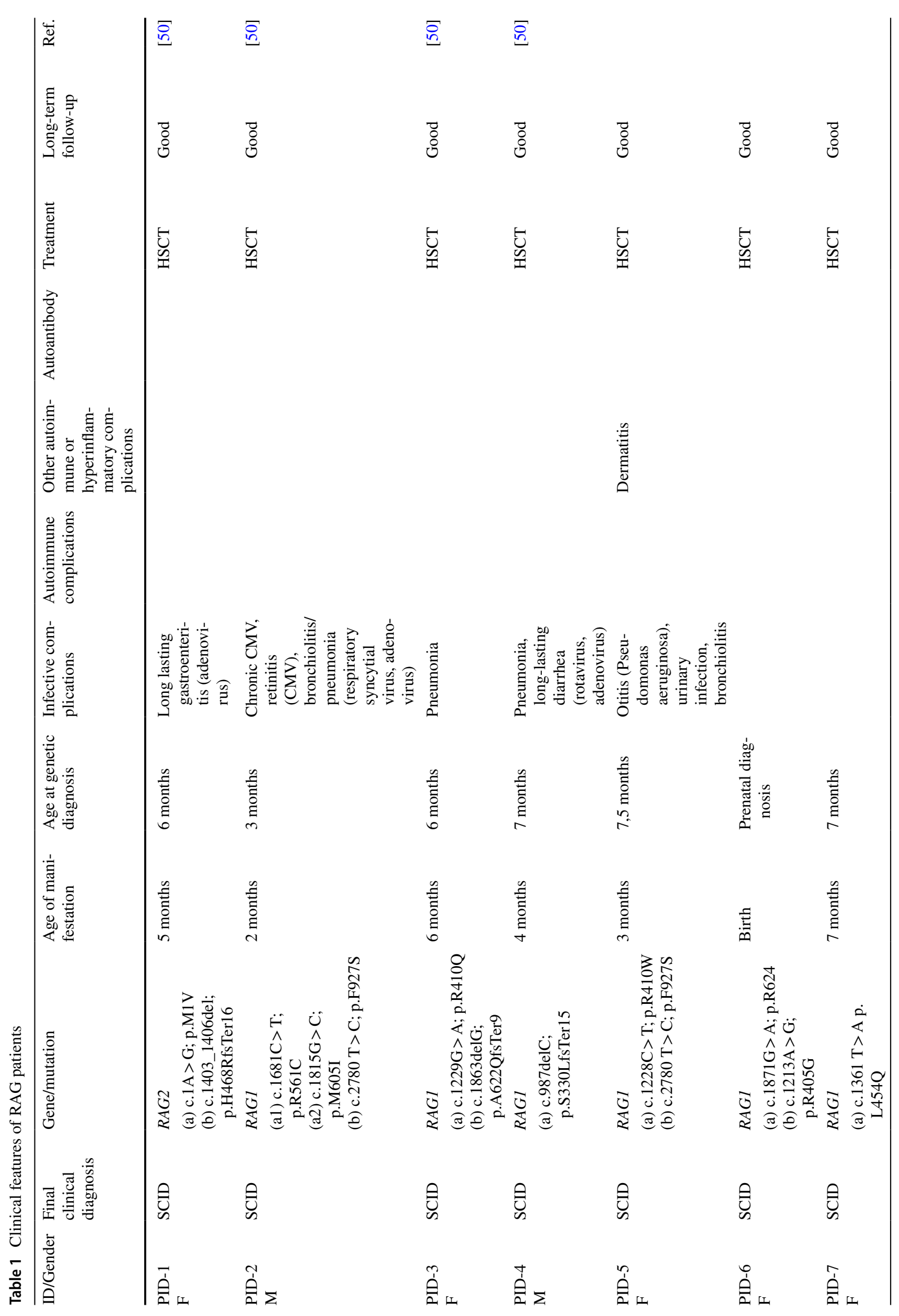




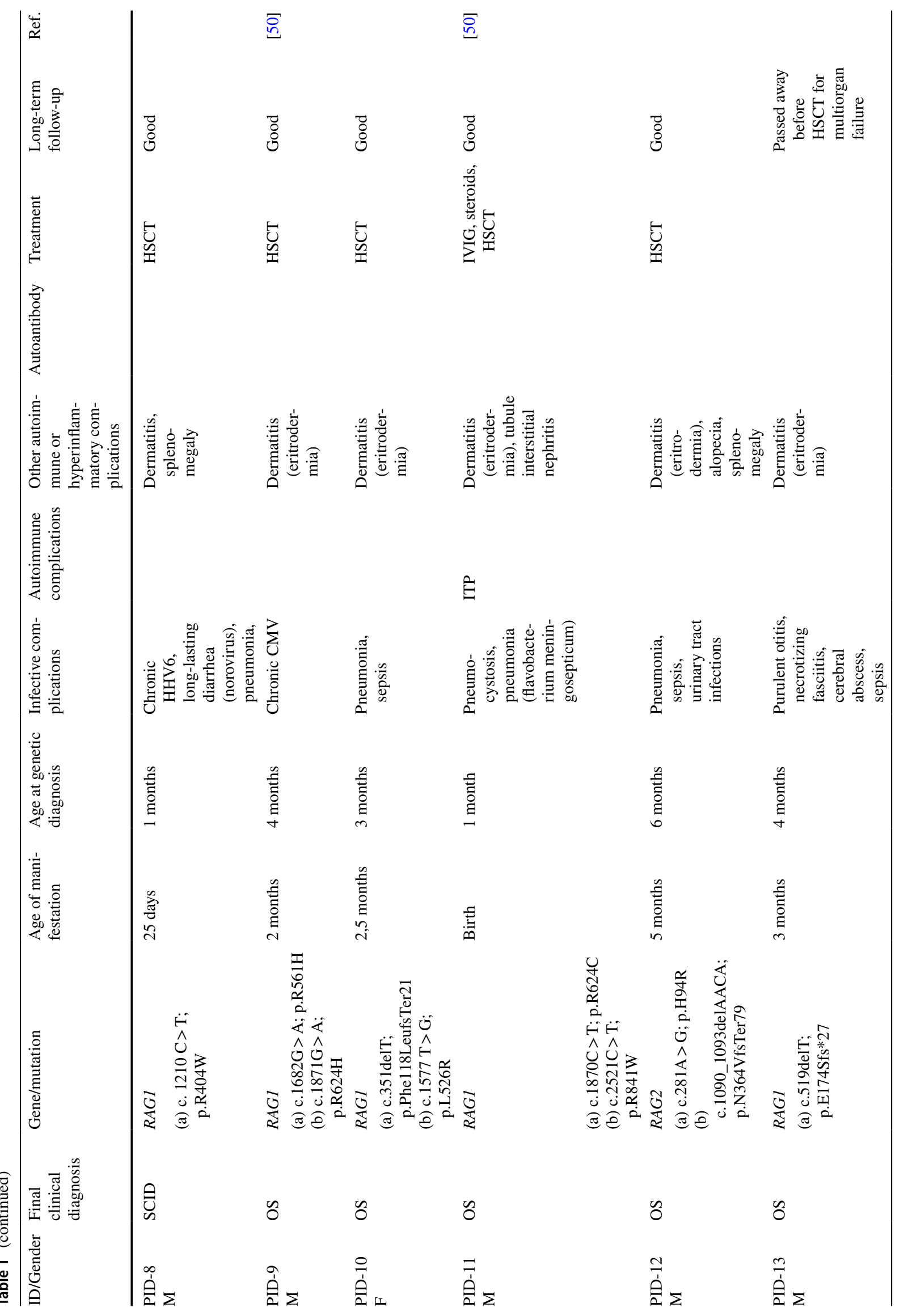




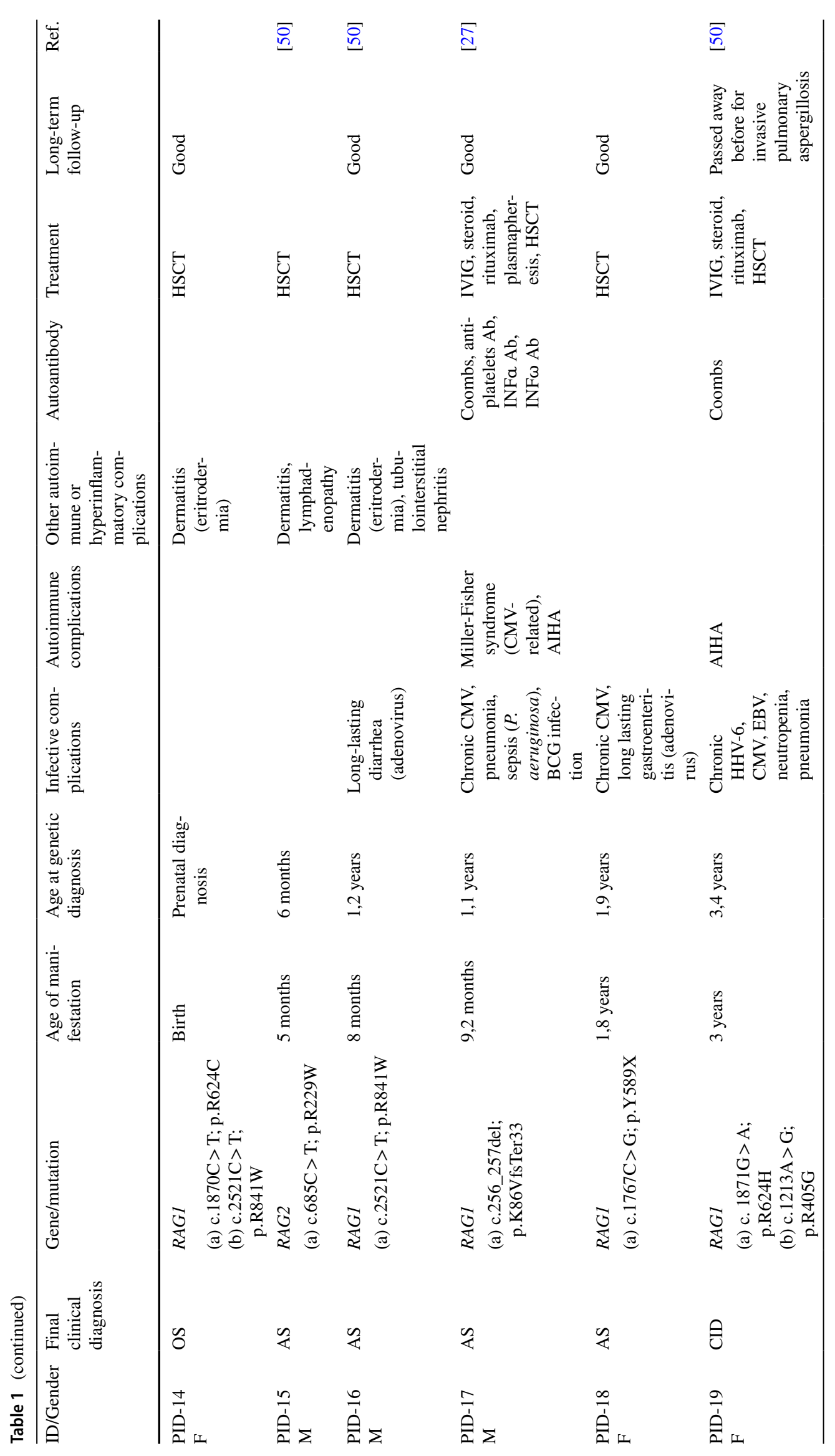




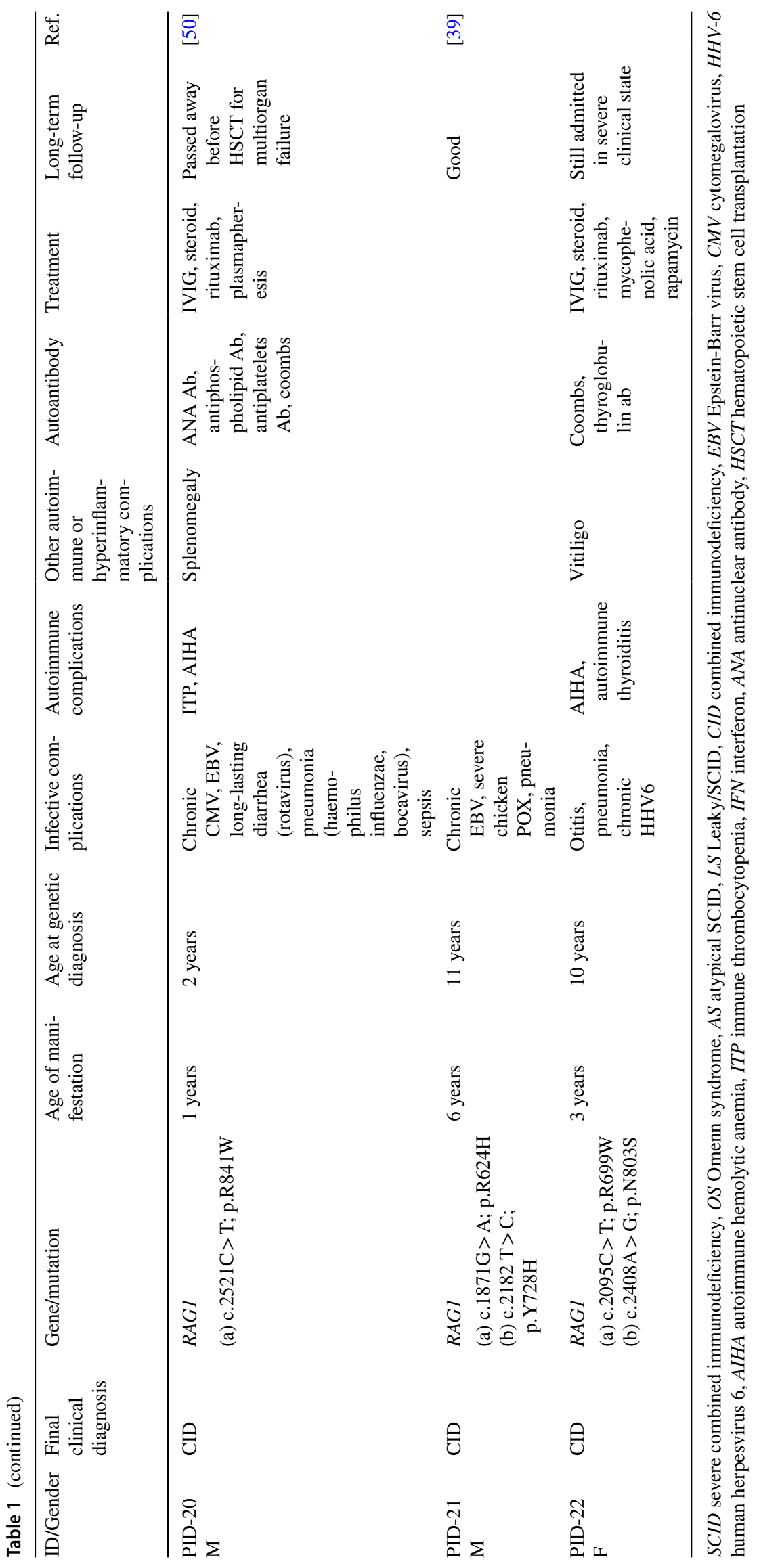




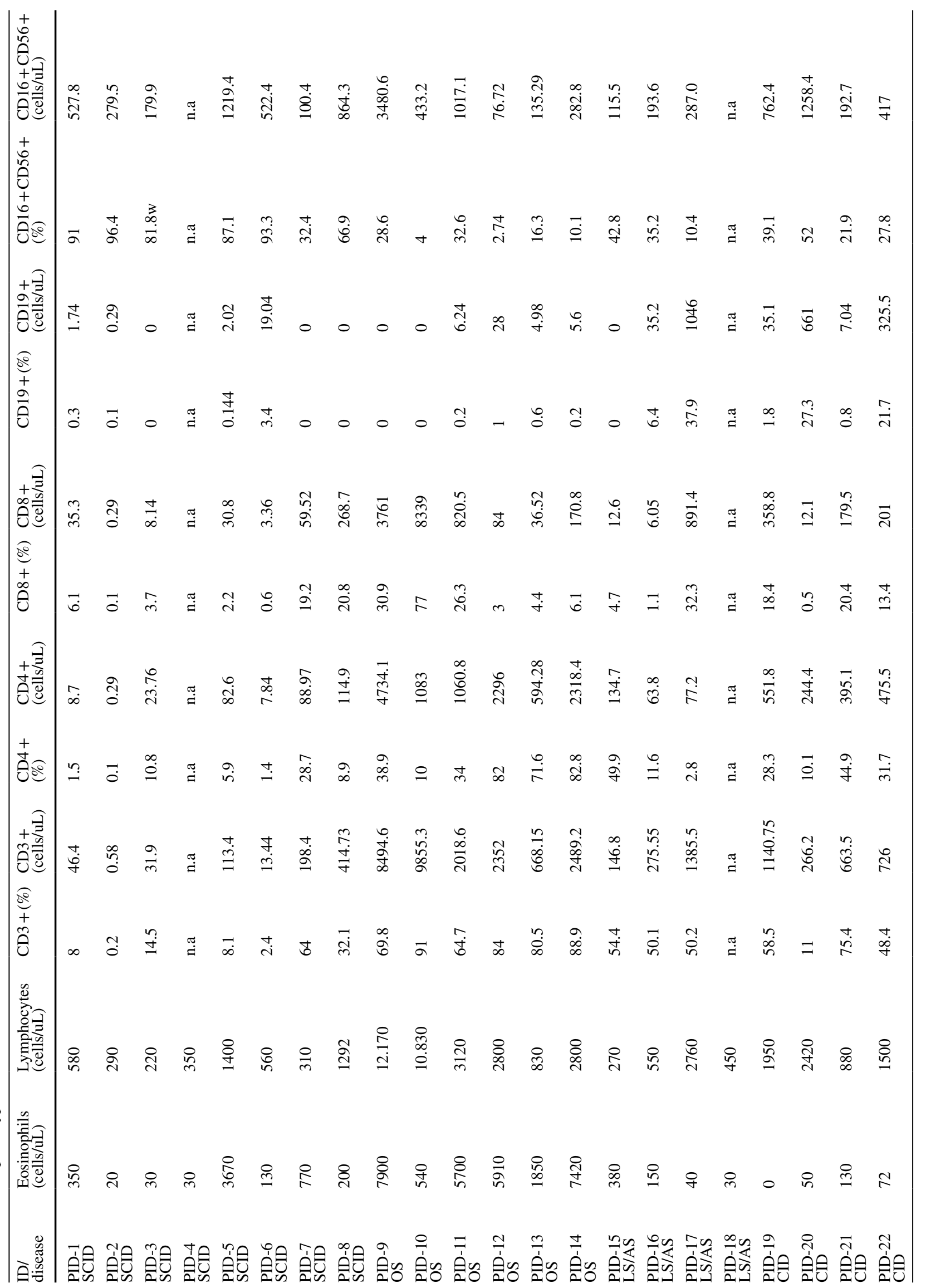




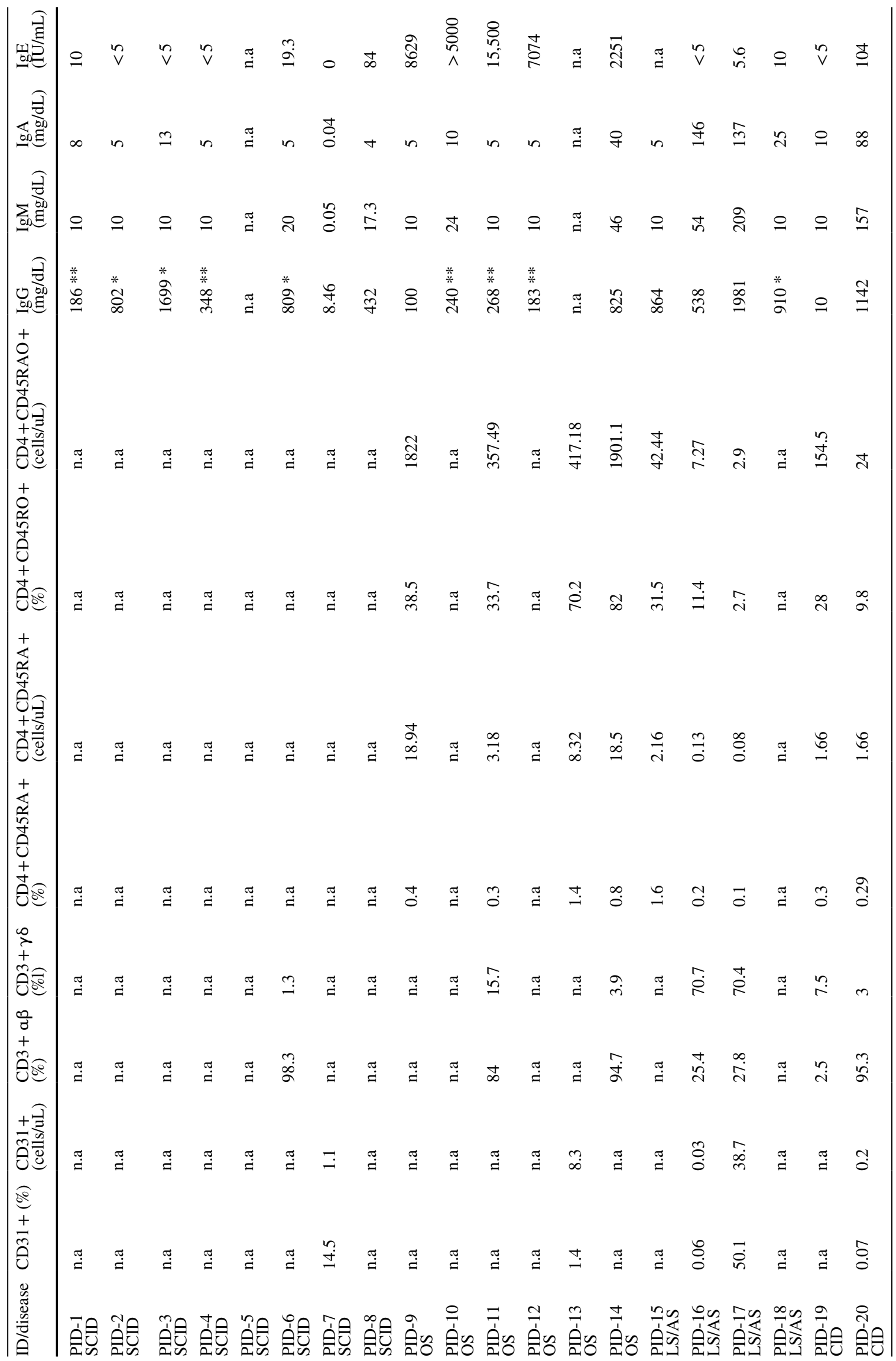




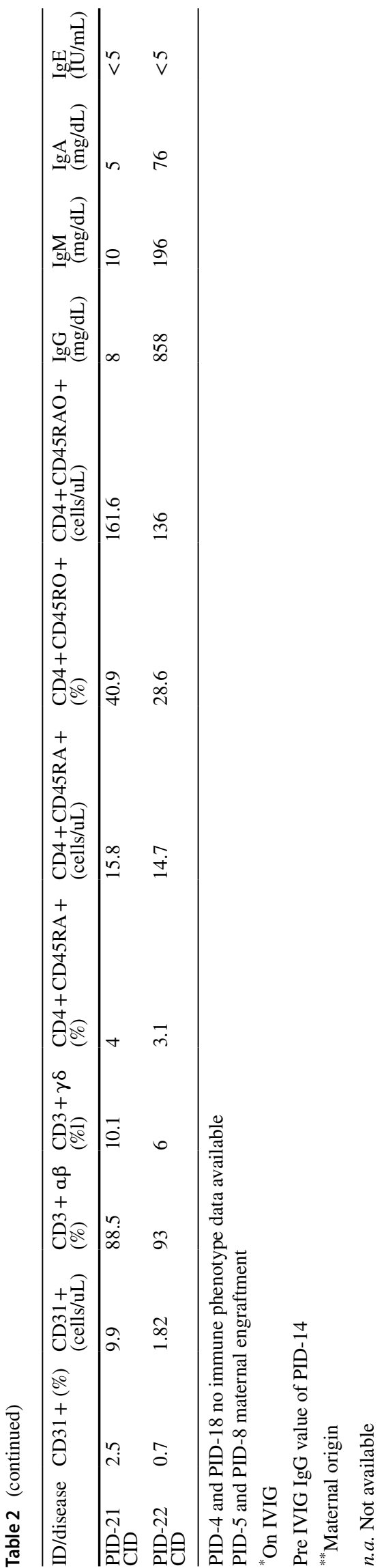

(Fig. 1B). The median age of the first symptom and the genetic diagnosis were markedly lower in SCID and OS than in LS/AS and mostly in CID patients (Fig. 1B).

The symptom at presentation was infection $(n=18$; 81.8\%). Dermatitis represented the onset manifestation in all OS, two LS/AS (PID-15, PID-16) and two SCID patients (PID-5, PID-8). On the other hand, infections, autoimmunity, and immune dysregulation occurred together in most cases $(n=12 ; 54.5 \%)$. Two SCID and one OS early diagnosed due to prenatal diagnosis or strongly suggestive phenotype were promptly transplanted and did not present any severe manifestation (Fig. 1D). Chronic viremia was common among the cohort (SCID $n=4$; OS $n=1$; LS/As $n=3$; CID $n=4$ ), whereas respiratory and gastrointestinal infections were prevalent in SCID patients (Fig. 1E). Interestingly, 15 out of $22(68.2 \%)$ patients presented autoimmune and/or hyperinflammatory manifestations (Fig. 1D). The most frequent was dermatitis occurring in 9 patients (40.9\%). Lymphoproliferation and splenomegaly were present in 4 patients (18.1\%). Nephropathy occurred in 2 patients (PID-14 and PID-16). whereas one patient developed Miller Fisher syndrome (PID-17) (Fig. S2, and Table 1).

Notably, one OS, one LS/AS, and 3 CID patients (PID12, PID-13, PID-17, PID-20, PID-10) with autoimmune/ inflammatory complications experienced a severe autoimmune cytopenia (AIC) (Fig. 2A) with a median age at onset of 1 year (range 1-9) (Fig. 2B).

RAG1 mutations were detected in nineteen $(86.4 \%)$ patients, while $R A G 2$ mutations in three (13.6\%) of them (Table S1). Consanguinity was documented in 9 out of 20 families (45\%), in which we found homozygous mutations. We found three novel mutations in RAGl gene (p.S330LfsTer15, p.R404W, and p.N803S) and two in RAG2 (p.H94R and p.N364VfsTer79). Combined Annotation-Dependent Depletion (CADD) scores have been used to define the degree of pathogenicity of novel mutations (Table S1).

\section{Immunological Phenotypes}

As expected, increased IgE levels were observed in OS group. IgA and IgM resulted very low or undetectable in SCID and OS patients, whereas detected serum IgG in two SCID and three OS reflected maternal trans-placental transfer. Leaky/atypical SCID and CID patients showed normal immunoglobulin values except for one patient with LS/AS, PID-17, who manifested hypergammaglobulinemia (Fig. S1A and Table 2).

Total lymphocyte counts were severely reduced or almost lacking in SCID group (Table 2).

$\mathrm{T}$ cells were particularly low in SCID group, whereas CD3, CD4, and CD8 cell count were higher in OS patients. LS/AS and CID patients presented detectable T cells, albeit 
reduced proportion of naïve T cells (Fig. S1B-C). Expansion of T-cell receptor $\gamma \delta$ was documented in two LS/AS patients (PID-16 and PID-17) (Fig. S1D), particularly following disseminated CMV infection as for PID-17. Circulating B cells were variably detected in AS and CID groups and were nearly absent as expected in SCID and OS patients correlating to their immunoglobulin levels. NK cells were present in all groups with normal or increased numbers (Fig. S1B).

\section{Outcomes and Treatment}

All patients with AIC received high dose of intravenous immunoglobulins (IVIG) and steroids as first-line therapy with limited response. No complete remission was observed in any patients despite second-line therapies with Rituximab (PID-12, PID-17, PID-20), mycophenolate mofetil (MMF) (PID-20), rapamycin (PID-22), or third-line therapies with plasmapheresis (PID-17, PID-20).

Eighteen out of 22 patients underwent allogenic HSCT with a median of 7 months (range 3-36.7) (Fig. 2C). Donors were either matched unrelated ( 2 cases, with one cord blood and one bone marrow as stem cell source), HLA-phenotypically identical ( 2 cases transplanted from the mother), or HLA-haploidentical (14 patients). Conditioning regimen was based on Treosulfan $42 \mathrm{gr} / \mathrm{m}^{2}$, fludarabine $160 \mathrm{mg} /$ $\mathrm{m}^{2}$, and ATLG, with 6 patients receiving additional tiotepa $10 \mathrm{mg} / \mathrm{kg}$.

Neutrophils and platelets engraftment were achieved in 16 out of 18 patients after a median time of 15 days and 11 days, respectively. Two patients experienced primary graft failure and were rescued with an allograft from the other HLA-haploidentical parent.

Cumulative incidence of grades I-II acute graft-versushost disease (aGvHD) was $17 \%(95 \% \mathrm{CI})$ with 3 patients experiencing mild, skin-only aGvHD. No cases of grades III-IV aGvHD were observed, and no patient experienced chronic GvHD. Infectious complications were frequent after HSCT, accounting for almost $90 \%$ of patients, and included blood stream infections (5 patients), viral reactivations (CMV, HHV6, and Adenovirus in 6, 2, and 4 patients, respectively), infectious enteritis (Rotavirus 1, Norovirus 1, and C. difficile 1 case), and invasive pulmonary aspergillosis (PID-19).

With a median follow-up of 61 months (range 17-138) overall survival of transplanted patients was $94 \%$ (95\% CI). One patient died of massive pulmonary hemorrhage caused by invasive aspergillosis which was already present at the time of HSCT. Noteworthy, two additional patients of our cohort died before HSCT due to multiorgan failure.

Notably, all patients reached normal immunoglobulin levels.

Among fifteen patients with autoimmune/hyperinflammatory manifestations, HSCT was required for definitive management in twelve patients (80\%). Patients with immune dysregulation underwent HSCT at an older age compared to those without immune dysregulation (median 12.7 vs. 7.4 years) partially due to the diagnostic delay (Fig. 2D). Two patients resolved treatment-refractory AIC, thanks to HSCT.

\section{Discussion}

During an 11-year period, we diagnosed 22 RAG patients at the Bambino Gesù Children's Hospital. The patients were classified as SCID, OS, LS/AS, and CID, confirming that different clinical phenotypes can be found in patients with identical mutations even within the same family.

We recorded an increased number of $R A G$ diagnosis following NGS application from a median of 1.5 up to 2.6 per year. This was particular evident in the first year of NGS application, in which we unmasked previous undiagnosed cases. This increased frequency is consistent with recent reports, including newborn screening that confirm $R A G 1 / 2$ as the second most prevalent genes associated with SCID and the most common genes associated with leaky SCID/CID [29]. In addition, we observed a median delay of 75 days between clinical onset and genetic diagnosis for SCID, 1 month for OS, 14 months for LS/AS, and 3 years for CID patients. As reported in other studies [22], the CID diagnostic delay reflects a lack of recognition of hypomorphic RAG mutations associated with milder and late onset phenotype in contrast to the severe SCID phenotype caused by null RAG mutations. These data confirmed a higher frequency of RAG defects that should be promptly suspected and recognized to avoid severe complications.

As reported [30,31], the immunological phenotype in our cohort confirmed the reduction of the $\mathrm{T}$ cell count and the diminished proportion of peripheral naive CD4 $\mathrm{T}$ cells in each group. Thus, a detailed immunophenotype could help in suspecting RAG deficiency in those patients with immune dysregulation.

$R A G 1$ mutations have been reported more frequently than $R A G 2[31,32]$ as occurred in our cohort. Interestingly, we found three novel mutations in the RAGl gene and two in $R A G 2$. Based on previously reported literature [33-35] that showed a significantly lower activity level of missense mutations in the nonamer-binding region (NBR) that is part of the catalytic core, we can assume that the p.R $404 \mathrm{~W}$ could explain the SCID phenotype observed in PID-8.

Similarly, the p.S330LfsTer15 mutation is found in PID-4 falls in the RING domain of RAG1, determining the absence of recombination activity by affecting protein subcellular localization or decreasing chromatin accessibility of the RAG complex [34, 35]; however, in this patient, the resulting truncated protein is the most evident cause 
A
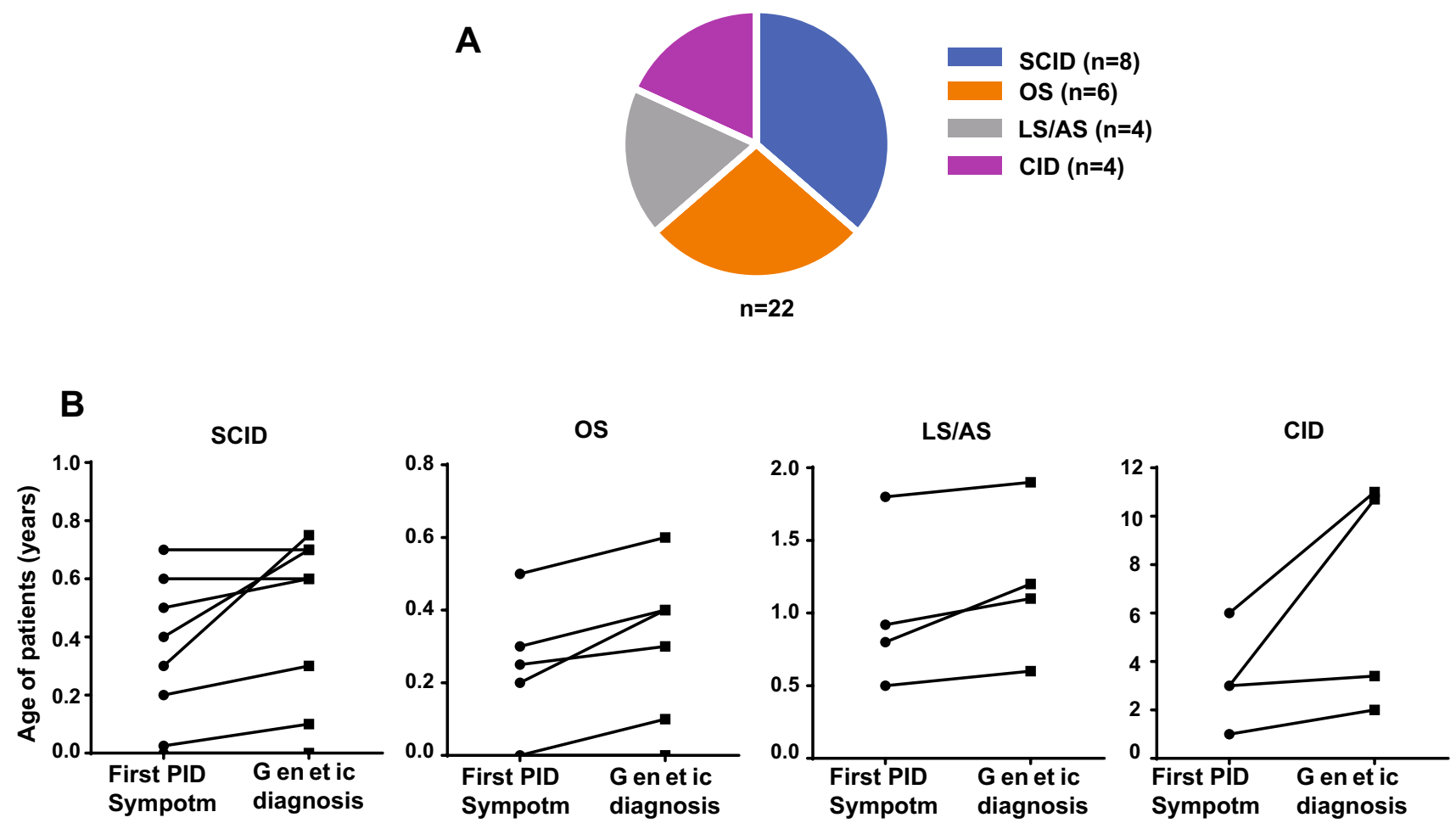

C

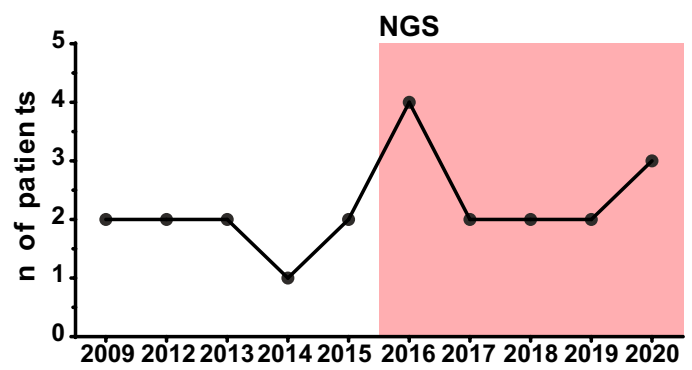

D

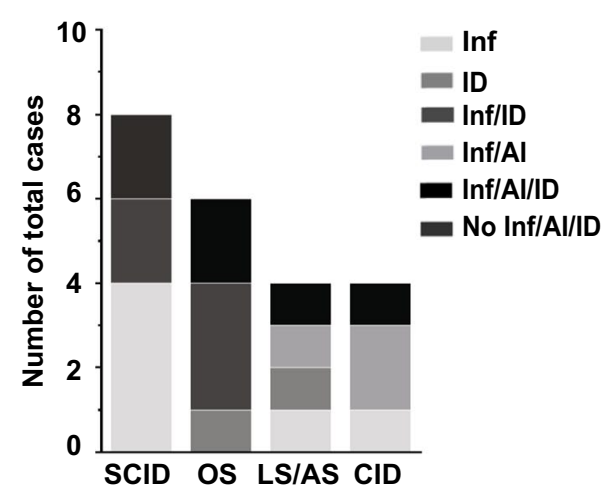

E

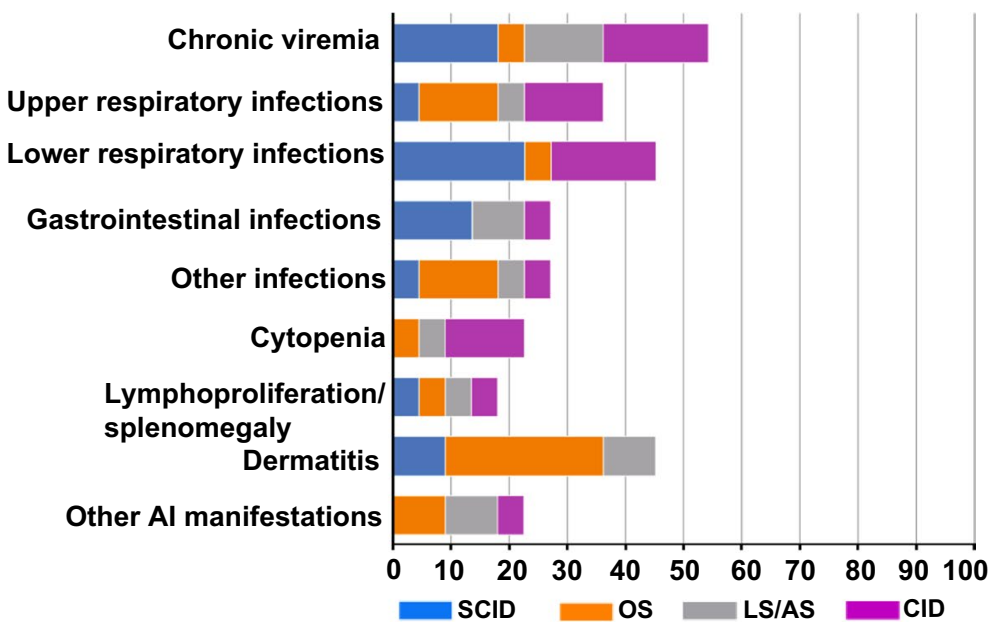


4 Fig. 1 a RAG cohort. Clinical diagnosis of RAG patients for the four main categories $(n=22)$. b Difference in timing for first symptom of immunodeficiency and genetic diagnosis of four RAG groups. Symbols represent individual patients. c Infections, autoimmunity, and immune dysregulation in RAG cohort (number of total cases). Inf, infection; ID, immune dysregulation; AI, autoimmune manifestation. d Clinical manifestations in RAG cohort distributed among the four groups (frequency as \% total cases). Other: Miller-Fisher syndrome, tubulointerstitial nephritis, alopecia, vitiligo. PID-6 prenatal diagnosis. PID-7 No available data during first months of life

of SCID phenotype. Moreover, the C-terminus of RAG1 protein has been identified primarily in patients with CID showing significant residual VDJ recombination activity [6]. These data perfectly reflect the p.N803S mutation carried by PID-22 characterized by a CID phenotype, although the recombination activity of this novel mutation was not yet determined. Finally, PID-12 carried the two novel p.H94R and p.N364VfsTer79 mutations, both in the extended catalytic core of the RAG2 protein that may affect its activity leading to an OS phenotype [36]. Also in this case, the p.N364VfsTer79 mutation causing an evident defective protein can more heavily affect the RAG2 function. Differently from other studies focused on populations with a high rate of consanguinity [37, 38], many patients enrolled in this work had non-consanguineous parents (59\%), suggesting a high mutation rate in these genes as well as a large occurrence of heterozygous carriers.

Interestingly, although individuals with $R A G$ heterozygous missense mutations were not reported to be typically associated to a RAG phenotype, we observed three CID patients presenting with autoimmune cytopenia and carrying only a single missense heterozygous mutation in $R A G$ genes (data not shown). These data suggest that other factors, not yet fully understood, could influence the disease expression.

PID-16 and PID-20, defined as LS/AS and CID, respectively, carried the same homozygous mutations (p.R841W), with severe autoimmune manifestations: the second one, despite having received a timely diagnosis, died before being able to undergo HSCT. Similarly, two compound heterozygous siblings (PID-6 and PID-19) (p.R405G and p.R624H) were diagnosed as SCID and CID, respectively. The older sister (PID-19) diagnosed at 3 years of life died of invasive aspergillosis already present at time of HSCT. The younger sister (PID-6) who received at birth a more severe diagnosis of SCID underwent HSCT at 3 months of life showing a different clinical outcome, thanks also to a prenatal diagnosis. This underlines the importance of other epigenetic or environmental factors on disease course and how a prompt HSCT may be crucial.

Furthermore, four compound heterozygous $R A G 1$ patients, classified as SCID (PID-6), OS (PID-9), and CID (PID-19, PID-21), shared the same p.R624H mutation, with almost absent recombination activity, in combination with the p.R405G, p.Y728H, and p.R561H respectively. The p.Y728H showed a markedly decreased but detectable recombination activity in line with his milder phenotype [39], whereas p.R561H showed nearly absent activity
Fig. 2 a Occurrence of autoimmune cytopenia in each RAG group. b Onset of AIC manifestation for PID-11,17,19,20,22. Autoimmune cytopenia (AIC), autoimmune neutropenia (AN), immune thrombocytopenia (ITP), autoimmune hemolytic anemia (AIHA). c Number of RAG diagnosis from 2009 to 2020. Pink background indicates the application of NGS. c Occurrence of HSCT in our RAG cohort. For each category, the total number of patients is indicated. d Occurrence of HSCT in patients with $(\mathrm{AI}+n=12)$ or without $(\mathrm{AI}-n=6)$ autoimmunity (frequency as \% annotated total cases. $n=18$ ) and age of HSCT
A

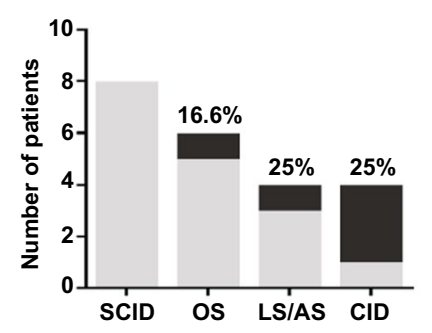

B

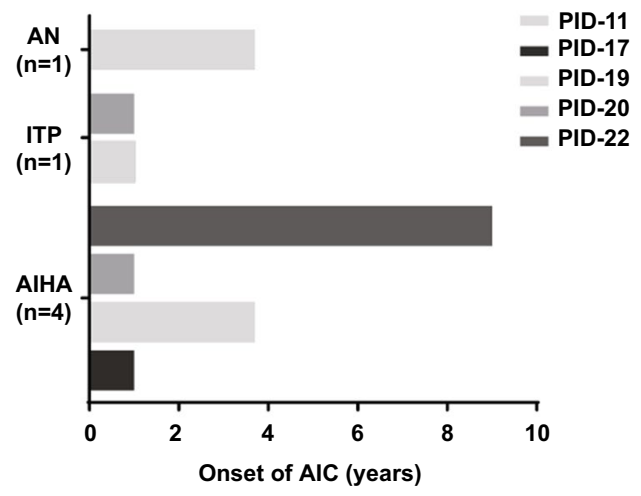

C

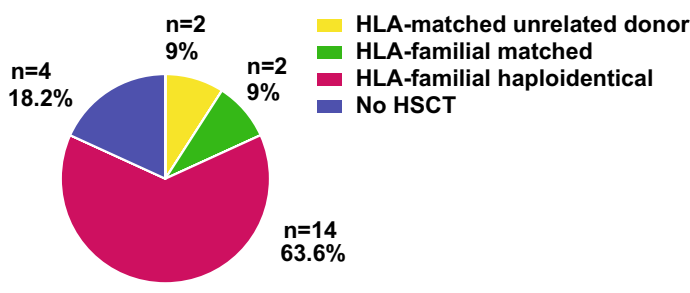


$(2.0 \pm 0.6)$ reflecting the OS disease. Unfortunately, the p.R405G recombination activity was not still determined. Otherwise, the two compound heterozygous brothers (PID-11 and PID-14) with the p.R624C and the p.R841W mutations presented with the same OS disease. Thus, genotype-phenotype correlation in RAG deficiency is not absolute. Indeed, other factors such as chronic and uncontrolled infections may influence the outcome of the disease besides the level of recombination activity determining a variable clinical phenotype even within the same family. CMV, EBV, and HHV-6 viral infections probably affected the clinical course and the onset of complications in PID-19. On the contrary, we cannot know what the clinical course would have been in PID-6 if she had encountered a virus before HSCT.

Indeed, chronic, uncontrolled Herpesviridae viremia was frequent among CID group (75\%). Usually, CID patients develop more severe manifestations often triggered by viral infections that closely preceded the onset of autoimmunity as in our patient PID-17 [40].

Nonetheless, the presence of residual B cells in CID patients makes them prone to EBV replication with higher risk of EBV-driven lymphoproliferation suggesting the need of a closer viral and radiological monitoring [41, 42].

PID-21 was initially classified as a humoral defect and only later reconsidered as CID at 11 years of age. Thus, considering the high frequency of hypomorphic mutations with a milder phenotype, a longitudinal re-evaluation of patients lacking a molecular diagnosis is always recommended, and RAG deficiency should also be suspected in patients where $\mathrm{B}$ cell defect is predominant. As rarely reported for other patients with CID phenotype [43], this patient did not undergo HSCT considering his good clinical status and the unsuccessful research for a suitable identical HSCT donor. He presented recurrent low respiratory infections well controlled by antibiotic prophylaxis (azithromycin) and immunoglobulin replacement therapy. This case underlines how the molecular definition could support pediatricians and immunologists in achieving better follow-up but open crucial questions on therapeutical options. Thus, a close followup in large multicentric international cohorts is mandatory to deepening the knowledge and understanding of these patients' natural history.

In line with other reports [22, 32], our data showed that severe immune dysregulation manifestations $(68.2 \%)$ are a common feature of RAG deficiency often refractory to conventional medical management. In particular, dermatitis and autoimmune refractory cytopenia resulted in the most frequent manifestations. Otherwise, nephritis [22, 32], or neurological involvement (Miller-Fisher syndrome) could represent the first or the main symptom of onset [30], which can lead patients to the attention of other specialist delaying the correct diagnosis. The early recognition of these manifestations could contribute to the choice of a prompt specific treatment and prevent the onset of others complications [43, 44].

According to the literature [22], given the refractory nature of autoimmune cytopenia, it is essential to rapidly proceed to transplant patients with AIC to avoid complications or chronic infections that can be responsible for the onset of comorbidities compromising the outcome of HSCT. HLA-identical donor transplant demonstrates an excellent overall survival greater than $75 \%[45,46]$. Moreover, innovative HSCT approaches have shown encouraging results in case when an HLA-matched donor is not available [47, 48]. Finally, immunosuppressive or immunomodulatory drugs should be strongly considered to control immunodysregulation in these patients.

\section{Conclusions}

RAG deficiency still presents a challenge in tracing effective management and follow-up, considering the inability to predict the disease course in atypical cases. This study describes the clinical, immunological, and molecular characteristics of $22 \mathrm{RAG}$ patients providing five novel mutations. This cohort highlighted the heterogeneity of manifestations associated with inborn error of immunity particularly for patients with hypomorphic mutations and milder phenotypes. In this regard, extending RAG analysis to older pediatric and adult patients affected by undefined CVID and/or immune dysregulation [42] might be helpful in discovering novel cases and expanding the current knowledge of natural history of $R A G$ deficiency.

Supplementary Information The online version contains supplementary material available at https://doi.org/10.1007/s10875-021-01130-3.

Acknowledgements The authors are grateful to patients and families. We also thank Dr Enrico Attardi for clinical assistance. We thank Jennifer Faudella, Patrizia Antimi, and Ilaria Pepponi for administrative assistance.

Author Contribution $\mathrm{CC}, \mathrm{BR}$, and $\mathrm{DA}$ interpreted the results and wrote the manuscript. CC, GMU, SDC, MC, MGD, MD, and GDM performed molecular and functional experiments and developed gene sequencing analysis. CC, GMU, and GDM created gene clusters to filter variants and integrated clinical and bioinformatics analysis of data retrieved by genetic platforms. DA, BR, LP, NC, MA, FG, GP, $\mathrm{PM}, \mathrm{FL}, \mathrm{PP}, \mathrm{PR}, \mathrm{AF}$, and $\mathrm{CaC}$ provided or referred clinical samples and patient's clinical data. CC, DA, BR, GDM, and $\mathrm{CaC}$ designed the research and participated in the study design and data interpretation. FL, PP, PR, AF, GDM, and $\mathrm{CaC}$ made substantial contributions to revising the manuscript. All authors have critically revised and approved the manuscript.

Funding The study was supported by grants of the Italian Ministero della Salute [NET-2011-02350069] to CaC, the Ricerca Corrente from Childrens' Hospital Bambino Gesù, Rome, Italy [RRC-2019-2366867] 
to $\mathrm{CaC}$, the Ricerca Corrente from Childrens' Hospital Bambino Gesù, Rome, Italy [RC2020_INFETT_FINOCCHI] to AF, and [RC2020_ INFETT_CANCRINI; 202105_INFETT_CANCRINI] to CaC.

Availability of Data and Material Not applicable.

Code Availability Not applicable.

\section{Declarations}

Conflict of Interest The authors declare no competing interests.

Ethics Approval This retrospective study involving human participants was in accordance with the ethical standards of the institutional and national research committee and with the 1964 Helsinki Declaration and its later amendments or comparable ethical standards. Informed consent was obtained from patient's parents/legal guardians.

Informed Consent Informed consent was obtained from patient's parents or legal guardians. Informed consent for publication was obtained from patient's parents or legal guardians.

Open Access This article is licensed under a Creative Commons Attribution 4.0 International License, which permits use, sharing, adaptation, distribution and reproduction in any medium or format, as long as you give appropriate credit to the original author(s) and the source, provide a link to the Creative Commons licence, and indicate if changes were made. The images or other third party material in this article are included in the article's Creative Commons licence, unless indicated otherwise in a credit line to the material. If material is not included in the article's Creative Commons licence and your intended use is not permitted by statutory regulation or exceeds the permitted use, you will need to obtain permission directly from the copyright holder. To view a copy of this licence, visit http://creativecommons.org/licenses/by/4.0/.

\section{References}

1. Notarangelo LD, Santagata S, Villa A. Recombinase activating gene enzymes of lymphocytes. Curr Opin Rheumatol. 2001;8:41-6

2. Hesslein DG, Schatz DG. Factors and forces controlling V(D)J recombination. Adv Immunol. 2001;78:169-232.

3. Gellert M. V(D)J recombination: RAG proteins, repair factors, and regulation. Annu Rev Biochem. 2002;71:101-32.

4. Helmink BA, Sleckman BP. The response to and repair of RAGmediated DNA double-strand breaks. Annu Rev Immunol. 2012;30:175-202.

5. Schatz DG, Oettinger MA, Baltimore D. The V(D)J recombination activating gene, RAG-1. Cell. 1989;59:1035-48.

6. Oettinger MA, Schatz DG, Gorka C, Baltimore D. RAG-1 and RAG-2, adjacent genes that synergistically activate V(D)J recombination. Science. 1990;248:1517-23.

7. Schwarz K, Gauss GH, Ludwig L, Pannicke U, Li Z, Lindner D, et al. RAG mutations in human B cell-negative SCID. Science. 1996;274(5284):97-9.

8. Villa A, Santagata S, Bozzi F, Giliani S, Frattini A, Imberti L, et al. Partial V(D)J recombination activity leads to Omenn syndrome. Cell. 1998;93:885-96.

9. Corneo B, Moshous D, Gungor T, Wulffraat N, Philippet P, Le Deist FL, et al. Identical mutations in RAG1 or RAG2 genes leading to defective $\mathrm{V}(\mathrm{D}) \mathrm{J}$ recombinase activity can cause either
T-B- severe combined immune deficiency or Omenn syndrome. Blood. 2001;97:2772-6.

10. Sobacchi C, Marrella V, Rucci F, Vezzoni P, Villa A. RAGdependent primary immunodeficiencies. Hum Mutat. 2006;27:1174-84.

11. Pasic S, Djuricic S, Ristic G, Slavkovic B. Recombinase-activating gene 1 immunodeficiency: different immunological phenotypes in three siblings. Acta Paediatr. 2009;98:1062-4.

12. Dalal I, Tasher D, Somech R, Etzioni A, Garti BZ, Lev D, et al. Novel mutations in RAG1/2 and ADA genes in Israeli patients presenting with T-B-SCID or Omenn syndrome. Clin Immunol. 2011;140:284-90.

13. Cassani B, Poliani PL, Moratto D, Sobacchi C, Marrella V, Imperatori L, et al. Defect of regulatory T cells in patients with Omenn syndrome. J Allergy Clin Immunol. 2010;125:209-16.

14. Villa A, Sobacchi C, Notarangelo LD, Bozzi F, Abinun M, Abrahamsen TG, et al. V(D)J recombination defects in lymphocytes due to RAG mutations: severe immunodeficiency with a spectrum of clinical presentations. Blood. 2001;97:81-8.

15. Schuetz C, Huck K, Gudowius S, Megahed M, Feyen O, Hubner $\mathrm{B}$, et al. An immunodeficiency disease with RAG mutations and granulomas. N Engl J Med. 2008;358:2030-8.

16. De Ravin SS, Cowen EW, Zarember KA, Whiting-Theobald NL, Kuhns DB, Sandler NG, et al. Hypomorphic Rag mutations can cause destructive midline granulomatous disease. Blood. 2010;116:1263-71.

17. Henderson LA, Frugoni F, Hopkins G, de Boer H, Pai SY, Lee $\mathrm{YN}$, et al. Expanding the spectrum of recombination-activating gene 1 deficiency: a family with early-onset autoimmunity. J Allergy Clin Immunol. 2013;132:969-71.e2.

18. Kuijpers TW, Ijspeert H, van Leeuwen EM, Jansen MH, Hazenberg MD, Weijer KC, et al. Idiopathic CD4+ T lymphopenia without autoimmunity or granulomatous disease in the slipstream of RAG mutations. Blood. 2011;117(22):5892-6.

19. Kato T, Crestani E, Kamae C, Honma K, Yokosuka T, Ikegawa $\mathrm{T}$, et al. RAG1 deficiency may present clinically as selective $\mathrm{IgA}$ deficiency. J Clin Immunol. 2015;35(3):280-8.

20. Geier CB, Piller A, Linder A, Sauerwein KM, Eibl MM, Wolf HM. Leaky RAG deficiency in adult patients with impaired antibody production against bacterial polysaccharide antigens. PLoS ONE. 2015;10(7):e0133220.

21. Chou J, Hanna-Wakim R, Tirosh I, Kane J, Fraulino D, Lee YN, et al. A novel homozygous mutation in recombination activating gene 2 in 2 relatives with different clinical phenotypes: Omenn syndrome and hyper-IgM syndrome. J Allergy Clin Immunol. 2012;130(6):1414-6.

22. Farmer JR, Foldvari Z, Ujhazi B, De Ravin SS, Chen K, Bleesing $\mathrm{JJH}$, et al. Outcomes and treatment strategies for autoimmunity and hyperinflammation in patients with RAG deficiency. J Allergy Clin Immunol Pract. 2019;7(6):1970-85. https://doi.org/ 10.1016/j.jaip.2019.02.038.

23. Chen K, Wu W, Mathew D, Zhang Y, Browne SK, Rosen LB, et al. Autoimmunity due to RAG deficiency and estimated disease incidence in RAG1/2 mutations. J Allergy Clin Immunol. 2014; 133(3):880-2.

24. Villa A, Notarangelo LD. RAG gene defects at the verge of immunodeficiency and immune dysregulation. Immunol Rev. 2019;287(1):73-90. https://doi.org/10.1111/imr.12713.

25. Shearer WT, Dunn E, Notarangelo LD, Dvorak CC, Puck JM, Logan BR, et al. Establishing diagnostic criteria for severe combined immunodeficiency disease (SCID), leaky SCID, and Omenn syndrome: the primary immune deficiency treatment consortium experience. J Allergy Clin Immunol. 2014;133(4):1092-8.

26. ESID.org. https://esid.org/Working-Parties/Registry-WorkingParty/Diagnosis-criteria. 
27. Walter JE, Rosen LB, Csomos K, Rosenberg JM, Mathew D, Keszei M, et al. Broad-spectrum antibodies against self-antigens and cytokines in RAG deficiency. J Clin Investig. 2015;125(11):413548. https://doi.org/10.1172/JCI80477. Erratum in: J Clin Investig. 2016;126(11):4389.

28. Shearer WT, Dunn E, Notarangelo LD, Dvorak CC, Puck JM, Logan BR, et al. Establishing diagnostic criteria for severe combined immunodeficiency disease (SCID), leaky SCID, and Omenn syndrome: the primary immune deficiency treatment consortium experience. J Allergy Clin Immunol. 2014;133:1092-8. https:// doi.org/10.1016/j.jaci.2013.09.044.

29. Kwan A, Abraham RS, Currier R, Brower A, Andruszewski K, Abbott JK, et al. Newborn screening for severe combined immunodeficiency in 11 screening programs in the United States. JAMA. 2014;312(7):729-38.

30. DelmonteO M, Schuetz C, Notarangelo LD. RAG deficiency: two genes, many diseases. J Clin Immunol. 2018;38(6):646-55. https://doi.org/10.1007/s10875-018-0537-4.

31. Greenberg-Kushnir N, Lee YN, Simon AJ, Lev A, Marcus N, Abuzaitoun O, et al. A large cohort of RAG1/2-deficient SCID patients-clinical, immunological, and prognostic analysis. J Clin Immunol. 2020;40(1):211-22. https://doi.org/10.1007/ s10875-019-00717-1.

32. Sharapova SO, Skomska-Pawliszak M, Rodina YA, WolskaKuśnierz B, Dabrowska-Leonik N, Mikołuć B, et al. The clinical and genetic spectrum of 82 patients with RAG deficiency including a c.256_257delAA founder variant in Slavic countries. Front Immunol. 2020;11:900. https://doi.org/10.3389/fimmu.2020.00900.

33. Lee YN, Frugoni F, Dobbs K, Walter JE, Giliani S, Gennery AR, et al. A systematic analysis of recombination activity and genotype-phenotype correlation in human recombination-activating gene 1 deficiency. J Allergy Clin Immunol. 2014;133(4):1099108. https://doi.org/10.1016/j.jaci.2013.10.007.

34. Santagata S, Gomez CA, Sobacchi C, Bozzi F, Abinun M, Pasic $\mathrm{S}$, et al. N-terminal RAG1 frameshift mutations in Omenn's syndrome: internal methionine usage leads to partial V(D)J recombination activity and reveals a fundamental role in vivo for the N-terminal domains. Proc Natl Acad Sci USA. 2000;97(26):14572-7.

35. Couedel C, Roman C, Jones A, Vezzoni P, Villa A, Cortes P. Analysis of mutations from SCID and Omenn syndrome patients reveals the central role of the Rag2 PHD domain in regulating V(D)J recombination. J Clin Investig. 2010;120(4):1337-44.

36. Notarangelo LD, Kim MS, Walter JE, Lee YN. Human RAG mutations: biochemistry and clinical implications. Nat Rev Immunol. 2016;16(4):234-46. https://doi.org/10.1038/nri.2016.28.

37. Meshaal SS, El Hawary RE, Abd Elaziz DS, Eldash A, Alkady R, Lotfy S, Mauracher AA, Opitz L, Pachlopnik Schmid J, van der Burg M, Chou J, Galal NM, Boutros JA, Geha R, Elmarsafy AM. Phenotypical heterogeneity in RAG-deficient patients from a highly consanguineous population. Clin Exp Immunol. 2019;195(2):202-12. https://doi.org/10.1111/cei.13222.

38. Al-Herz W, Massaad MJ, Chou J, Notarangelo LD, Geha RS. DNA recombination defects in Kuwait: clinical, immunologic and genetic profile. Clin Immunol. 2018;187:68-75.

39. Cifaldi C, Scarselli A, Petricone D, Di Cesare S, Chiriaco M, Claps A, et al. Agammaglobulinemia associated to nasal polyposis due to a hypomorphic RAG1 mutation in a 12 years old boy. Clin Immunol. 2016;173:121-3. https://doi.org/10.1016/j.clim.2016. 09.013 .
40. de Villartay JP, Lim A, Al-Mousa H, Dupont S, Déchanet-Merville J, Coumau-Gatbois E, et al. A novel immunodeficiency associated with hypomorphic RAG1 mutations and CMV infection. J Clin Investig. 2005;115(11):3291-9. https://doi.org/10.1172/ JCI25178.

41. Ehl S, Schwarz K, Enders A, Duffner U, Pannicke U, Kuhr $\mathrm{J}$, et al. A variant of SCID with specific immune responses and predominance of gamma delta $\mathrm{T}$ cells. J Clin Investig. 2005;115(11):3140-8.

42. Lawless D, Geier CB, Farmer JR, Allen HL, Thwaites D, Atschekzei F, et al. Prevalence and clinical challenges among adults with primary immunodeficiency and recombination-activating gene deficiency. J Allergy Clin Immunol. 2018;141(6):2303-6. https:// doi.org/10.1016/j.jaci.2018.02.007.

43. Cifaldi C, Ferrua F, Aiuti A, Cancrini C. Hematopoietic stem cell gene therapy for the cure of blood diseases: primary immunodeficiencies Rendiconti Lincei. Scienze Fisiche e Naturali. 2018;29:755-64.

44. Hadjadj J, Aladjidi N, Fernandes H, Leverger G, Margérus-Chatinet A, Mazeroolles F, et al. Pediatric Evans syndrome is associated with a high frequency of potentially damaging variants in immune genes. Blood. 2019;134(1):9-21. https://doi.org/10.1182/ blood-2018-11-887141.

45. Buckley RH. Molecular defects in human severe combined immunodeficiency and approaches to immune reconstitution. Annu Rev Immunol. 2004;22:625-55.

46. Dvorak CC, Hassan A, Slatter MA, Honig M, Lankester AC, Buckley RH, et al. Comparison of outcomes of hematopoietic stem cell transplantation without chemotherapy conditioning by using matched sibling and unrelated donors for treatment of severe combined immunodeficiency. J Allergy Clin Immunol. 2014;134(4):935-43.

47. Bertaina A, Merli P, Rutella S, Pagliara D, Bernardo ME, Masetti $\mathrm{R}$, et al. HLA-haploidentical stem cell transplantation after removal of $\alpha \beta+\mathrm{T}$ and $\mathrm{B}$ cells in children with nonmalignant disorders. Blood. 2014;124(5):822-6. https://doi.org/10.1182/ blood-2014-03-563817.

48. Neven B, Diana JS, Castelle M, Magnani A, Rosain J, Touzot F, et al. Haploidentical hematopoietic stem cell transplantation with post-transplant cyclophosphamide for primary immunodeficiencies and inherited disorders in children. Biol Blood Marrow Transpl. 2019;25(7):1363-73. https://doi.org/10.1016/j.bbmt. 2019.03.009.

49. Moschese V, Lorenzini T, Chini L, Graziani S, Commissione di immunologia della S. Approccio diagnostico ai difetti della risposta anticorpale. Rivista di Immunologia e Allergologia pediatrica. 2017;1:8-18.

50. Cifaldi C, Brigida I, Barzaghi F, Zoccolillo M, Ferradini V, Petricone D, et al. Targeted NGS platforms for genetic screening and gene discovery in primary immunodeficiencies. Front Immunol. 2019;10:316. https://doi.org/10.3389/fimmu.2019.00316. Erratum in: Front Immunol. 2019;10:1184.

Publisher's Note Springer Nature remains neutral with regard to jurisdictional claims in published maps and institutional affiliations. 